\title{
Teacher Reflection in Literacy Education- Borrowing from Bakhtin
}

\author{
Soyong Lee ${ }^{1}$, Ph.D. \& Seungho Moon ${ }^{2}$, Ed. D. \\ ${ }^{1} \mathrm{Ph}$. D., Associate Professor of Literacy Education, Esteves School of Education, The Sage Colleges, $611^{\text {st }}$ Street, \\ Troy, NY 122180, USA \\ 2 Ed. D., Assistant Professor of Curriculum Studies, 239 Willard Hall, School of Teaching and Curriculum \\ Leadership (STCL), College of Education, Oklahoma State University, Stillwater, OK 74078-4042, USA
}

Correspondence: Soyong Lee, Ph. D. , Associate Professor of Literacy Education, Esteves School of Education, The Sage Colleges, $611^{\text {st }}$ Street, Troy, NY 122180, USA. Tel: 1-518-244-2370. Fax: 1-518-244-2334. E-mail: lees2@sage.edu

Received: August 22, 2013

Accepted: September 21, 2013

Online Published: October 29, 2013

doi:10.5430/ijhe.v2n4p157

URL: http://dx.doi.org/10.5430/ijhe.v2n4p157

\begin{abstract}
In this article, we introduce Bakhtin's (1981) idea of revoicing and situate our data drawn from a graduate literacy methods course for in-service teachers in the United States in this framework. This study is exploratory in nature. We use data from a single literacy methods class to explore and shed light on the "how-to" of teacher reflection using a Bakhtinian framework. As teacher educators, we believe that introducing new frameworks and perspectives that enable professionals to dismantle the binary of theory and practice by putting reflection into action is of high priority for the field.

We discuss in detail an activity in a literacy methods class that requires the in-service teachers to put the idea of culturally relevant teaching (Ladson-Billings, 1994) into action by dramatizing a read-aloud in a childhood classroom, and to observe and analyze what happens when an idea from a class reading (culturally relevant teaching) takes a dimensional spin into practice (a dramatized classroom scenarios). In doing so, the in-service teachers were challenged to reinterpret and revoice the concept of "culturally relevant teaching" to meet the realities of their own classrooms and their own pedagogical tales (Dyson, 2002). The main purpose of this paper is to contribute to the literature on teacher reflection by shifting the focus from theorizing about teacher reflection to the enactment of teacher reflection.
\end{abstract}

Keywords: Teacher reflection, Bakhtin, Revoicing, Literacy methods, Theory into practice

\section{Introduction}

More than a century ago, John Dewey, in his book "How we think" (1910/1933), laid the foundation for much of the inquiry in the field of teacher reflection. Through reflection, teachers examine various aspects of educational phenomena (Dewey, 1910/1933). Dewey (1910/1933) defines reflection as a vehicle for knowledge growth and acknowledges that reflective thoughts make it possible for educators to know what we are about when we act. Reflection transforms action that is merely meaningless into intelligent actions. By thinking reflectively, the subject has the potential to convert an ambiguous situation into one that is coherent and harmonious. Reflection is an active process, which involves open-mindedness, wholeheartedness, and responsibility (Dewey, 1910/1933).

Since then reflection has held a central place within teacher education. The most compelling reason for this may be that reflection leads us to notice and act upon areas that may often go unnoticed or ignored (Milner, 2003). Donald Schön (1983), another prominent figure in the field of reflection, coined the term, "reflective practitioners" and illuminated the importance of conceptualizing knowledge and action, or theory and practice, as existing on a continuum by highlighting the role of reflection implemented both during and after the action. Schön conceptually differentiates reflection-in-action and reflection-on-action, depending on the time of reflection. The former happens during the action, while the latter refers to revisiting his/her knowledge frame used to cope with issues after the action. Schön's (1983) contribution in teacher research is seminal. It was through Schön's research that teacher educators saw how implementing reflection was a means to advance teacher professionalism.

A consensus exists in the field of teacher education that teachers develop their professionalism consciously and 
creatively through reflection. (Feiman-Nemser, 2001; Schön, 1983). Especially in the last decade, in the United States where this study is situated, the idea of reflection has taken on even more weight as a tool to counter the political climate of high-stakes testing and accountability that has brought on waves of prescribed curricular into the public schools (Ward \& McCotter, 2004). Education reform movements such as the No Child Left Behind Act of 2001 (NCLB), a standards-based education reform, now mandates all children from grades $3-8$ to be tested annually (http://www2.ed.gov/nclb/landing.jhtml). These standardized exams are high stakes for the students but also for the teachers as they are used as a tool in evaluating teachers, principals, and the school community and many teachers are under pressure to "teach to the test". Curricular that focuses on test preparation tend to leave very little room for teachers' professionalism or teacher reflection and have been criticized for positioning teachers as mere deliverers of information (Sizer, 2004).

Despite the central role that reflection plays within the field of teacher education, however, there is general consensus among teacher educators that reflection is a complex and confusing term (Jay \& Johnson, 2002). It is difficult to understand and even harder to teach. Merely requiring teacher candidates to keep a reflective journal does not seem to work effectively to advance their pedagogical knowledge (Seo, 2005). Over the years, reflection has crisscrossed with different social, cultural, and political ideas, adding to the diversity of the meanings of the term. As a result, understanding reflection and untangling the confusing morass of meaning poses a challenge for teacher educators.

As teacher educators, we have grappled with the idea of reflection in our teacher education courses. Under the current political climate of high-stakes testing and the push for back-to-the-basics/scripted curricula in the United States, we have become increasingly aware of and attuned to the heightened teacher voices that emerge from the intersection of theory and practice and where the reality of overcrowded and underserved classrooms cross with neatly organized conceptual frameworks introduced in educational textbooks. In many of the U. S. K- 12 schools, teachers are handed ready-made instructional materials, such as scripted reading programs that they are mandated to follow, while at the other end, in teacher education courses, they read and are encouraged to engage in discussions of child agency, culturally relevant teaching, and the need for a permeable curriculum (Dyson, 1993, 2008). We strongly believe that the tension that teachers experience within such spaces, between what they learn during their teacher education programs and what is practiced in schools, renders opportunities for meaningful discussions related to the implementation of teacher reflection (Seo, 2005). It is this contentious space that we zoom in on in this paper.

We introduce Bakhtin's (1981) idea of revoicing and situate our data drawn from a graduate literacy methods course for in-service teachers in this framework. Using Bakhtin's notion of revoicing to reinterpret the idea of reflection helps shed light on the how-to of reflection. This study is exploratory in nature. We use data from a single literacy methods class to explore and shed light on the "how-to" of teacher reflection using a Bakhtinian framework. The data that we depict in this article is from a literacy methods course where the candidates are grappling with the integration of theory and practice. As teacher educators, we believe that introducing new frameworks and perspectives that enable professionals to dismantle the binary of theory and practice by putting reflection into action is of high priority for the field. Reflection and action can "bridge" the gap between educational theory and practice (Mewborn, 1999). The main purpose of this paper is to contribute to the literature on teacher reflection by shifting the focus from theorizing about teacher reflection to the enactment of teacher reflection.

\section{Revoicing: A Bakhtinian Framework}

The word in language is half someone else's. It becomes "one's own" only when the speaker populates it with his own intentions, his own accent, when he appropriates the word, adapting it to his own semantic and expressive intention. Prior to this moment of appropriation, the word does not exist in a neutral and impersonal language, but rather it exists in other people's mouths, in other people's contexts, serving other people's intentions: it is from there that one must take the word, and make it one's own (Bakhtin, 1981, pp. 293-294).

According to Bakhtin (1981), we are all borrowers of other's words. Whenever one uses words to communicate, we are engaged in a dialogue with those from the past whom we are borrowing from-who have populated the words with meaning - and those in the future who will be borrowing from us. We become participants of an on-going dialogue, a "link in the chain of speech communication" (Bakhtin, 1986, p. 94). The process of borrowing, however, is not the process of merely repeating others' words in our own speech. In borrowing, we reappropriate, recontextualize, and resituate words to fit the needs of our own intentions. In other words, we engage in a process of revoicing. Such work involves active engagement with others' meanings as well as with one's own meanings and intentions.

In this paper, we extend the meaning of Bakhtin's "word" to mean texts, mainly the books and articles that we use in our teacher education classes. From a Bakhtinian perspective, then, the readings in our teacher education classes are 
like other's words to our students. To borrow from Dyson (2002), the examples of classroom practices in our texts are other's pedagogical tales. The classroom stories may often seem like an idealized version of classroom practice, or a thing of the past, often of the good times. In her work with urban teachers, Dyson discusses the "particularities" of teacher stories and offers a sound explanation to the value and the role of teachers' stories within the larger field of teacher education. To quote her in length,

But such [teacher] stories like the rawer "notes in a bottle" offered collegially in conversation, are of no use in and of themselves. Stories are not prescriptions for practice; they are material to think with (Geertz, 1973), whether the ultimate goal is to consider pedagogical decisions to help this child or that one, or to probe some theoretical puzzle about school learning. All stories become useful when they inform the telling of another's tale, when they become part of the chain of communication about teaching and learning (Dyson, 2002, p. 18).

The readings presented in our teacher education classes, like the stories Dyson describes, are not intended as examples of "best practices" to follow. The stories in the texts are an invitation for other stories from other places. A message exists in the readings about the nature of how human beings communicate and learn, of how we, as teachers, tend to act and react upon our students' efforts, and possibly a hidden message about the workings of social justice and equity within educational institutions. The stories are a starting point in becoming aware of issues and experiences in our own classrooms, of taking a different perspective on a familiar issue, or of thinking about new possibilities for what has become status quo in our teaching and learning environment. Though we may share in some parts of the stories, prior to one's active engagement with the stories, of "populat[ing] it with his own intentions, his own accent" (Bakhtin, 1981, p. 293) the stories carry little meaning. They are other's stories in other places, from other times.

The classroom activity below is from a graduate literacy methods course in which in-service teachers (Note 2) and a teacher educator grapple with the idea of what other's pedagogical tales means to one's own practice and the process of reflection that sheds light on understanding the connection between theory and practice.

\section{The Findings}

\subsection{Teaching reflection through revoicing}

But I think, what's the relevance of this, to my kids, my teaching? I like the class readings and they're interesting to read but I am not sure how I can use this information, or the examples, the teaching examples, in my own classroom. They're so different. (Karen (Note 1), 3rd year kindergarten teacher).

The above comment is from Karen, a kindergarten teacher in her mid-twenties who teaches in a middle-class suburban school. Karen is also a student in one of the author's literacy methods graduate courses. As is evident in her comment, Karen does not see the connection between many of the readings that she does in her graduate classes and her teaching. This was also true for many other literacy teacher candidates in this class as evidenced through comments during class and their reading reflection journals. Some of the class readings - the pedagogical tales-were close enough to Karen's own classroom realities (early childhood, middle-class neighborhood, mainstream, a balanced-literacy program) that she could readily use them to inform her own practice. However, for a majority of the readings in this graduate literacy course, this was not the case and Karen was having a hard time understanding what to make of such reading assignments. She was concerned about the application of class readings to her own classroom teaching.

The classroom activity below was an effort to address the concern that Karen raises in her comment above and to help the literacy teacher candidates see how the connections can be made possible through reflection. The activity is one that requires the teacher candidates to dramatize - to act out - a classroom scenario. We believe that a dramatized activity is effective in exercising teacher candidates' knowing-in-action, which is a key component in being a reflective practitioner. By "revoicing" the contents of the readings into situations, the teacher candidates are able to closely mirror their own classroom environment and connect readings to their own practices.

\subsection{The activity}

In this graduate literacy methods course, the teacher candidates were assigned two chapters (chapter 1 and 2) from Gloria Ladson-Billings' book, The Dreamkeepers (1994). The goal of this lesson was to explore the notion of culturally relevant teaching as explained by Ladson-Billings and the connection it may have in the teaching of reading and writing, primarily in the K-3 classrooms. The instructor also asked her students to bring a multicultural children's book to class to use in the small group work that would follow the whole group discussion.

The central focus of The Dreamkeepers (1994) is the idea of culturally relevant teaching. A teacher who adopts the 
holistic notion of culturally relevant teaching sees students' home culture, educational history, and personal background as being relevant to the curriculum and helps students become aware of and critically examine the various socio-cultural issues inherent in curricular materials. Culturally relevant teaching is a pedagogy that enables students to use cultural referents to connect to materials and lessons and develop not only intellectually but also emotionally, socially, and politically. Ladson-Billings illustrates these points through examples of successful master teachers in largely urban classrooms.

Prior to this activity, the class also read and discussed a chapter from Bakhtin's (1981), The Dialogic Imagination. The central concept of Bakhtin's chapter was "revoicing" and the class focused on understanding this idea within the context of reading and writing as well as teacher reflection.

On the day they were assigned The Dreamkeepers (Ladson-Billings, 1994), the class discussion began with comments and questions about the two assigned chapters. From this discussion, concepts and ideas emerged that were used as anchoring points for the activity to follow. The initial whole group discussion appeared to go well: Everyone seemed to understand that "culturally relevant teaching" was an important notion for teachers and that culture had meanings beyond language and ethnicity. Candidates commented on certain aspects of Ladson-Billings' work, mainly on the examples that she presents of successful urban teachers. They discussed how challenging it may be to teach reading and writing when students do not speak standard English and what it would mean for these same students to read and write in a way different from the way they speak. Many of the candidates pointed to the ways in which the teacher depicted in the chapter was able to use culturally relevant rap music in her English lesson on standard English. The discussion was lively and engaging. Following this whole-group discussion, the candidates broke up into small groups for small group work.

This small group work was intended to put "ideas into action" and to observe and analyze what happens when what is seen on paper (class readings) takes a dimensional spin into practice (dramatized classroom scenarios). From the instructor' point of view, the objective of the lesson was to help students infuse the ideas of culturally relevant pedagogy into a very popular literacy event, a read-aloud. The other larger objective was to provide opportunities for both reflection-in-action and reflection-on-action based on the idea of revoicing.

The small group activities in this graduate literacy course have a predictable format. There is a question that reiterates some aspects of the class reading into a real life classroom scenario. The candidates are asked to talk through the questions and then to be ready to act out/role play their responses. Doing so often requires the them to assign themselves roles as teachers, students, and in some cases, parents. Indeed, the simulations in our graduate classes are limited in many ways: Though the teachers may be real teachers, the people acting as K-6 students are teacher candidates, which means it lacks the chaotic and unpredictable nature of a group of children. "It's not the real thing," as one student put it. Despite such shortcomings, however, role playing a scenario enables participants to be closer to the real thing (the realities of classrooms), and it pushes them to think across different dimensions, namely, from the theoretical dimension to the dimension of practice. In other words, it forces them to revoice the contents of the readings using their own words and own realities. Also, as Schön (1987) put it, there are certain knowings that can only be revealed through action and performance.

In this small group activity that was a part of the overall lesson of culturally relevant teaching, candidates were grouped according to the grade levels they teach, they are familiar with, or ones they plan to teach in the coming future. A handout with the following instructions was distributed.

Instructions for Small Group Activity

You will be role-playing a "read-aloud lesson" with your peers using one of the children's books that you brought with you. The main purpose of this activity is to integrate "culturally relevant pedagogy" with practice as you conduct a read-aloud. Give meaning to this concept and make it relevant to your teaching situation. In other words, "revoice and reappropriate" the concept as you put it to use in this literacy event.

1. Share the multicultural children's book with your group and be ready to role play the read aloud for the class.

2. Decide on a book that you want to use for this activity.

3. Talk about what culturally relevant teaching would look like in the context of a read aloud within the classrooms that you currently teach in. What are the specific dimensions of culture that the teacher needs to be sensitive to? What are the principles/aspects of culturally relevant teaching, as explained by Ladson-Billings, that would apply to this literacy event?

4. Also discuss the idea of "revoicing" from Bahktin that we read a few weeks ago. Employ his idea of revoicing to 
the process.

In small groups, the instructor observed the literacy teacher candidates engaged in discussions "about" the books they brought. The multicultural children's books were about various ethnic groups (Sandoval, 1996; Ringgold, 1995; Takabayashi, 2001).

\subsection{The discussion and role playing}

When it came to discussing how they would infuse the idea of "culturally relevant teaching" in the reading of the book the in-service teachers seemed at a loss, as evidenced in the discussion below. Jen, an in-service teacher, raised her hand and asked for help.

Jen: We're a little lost here...do you want us to act, act out, like we're talking about the different culture in the book to the kids? Teaching about the different culture to the students? Make the culture in the book relevant to the kids that we're reading to?

The instructor: Well, that may be a part of it also, but...

Jen: Then, you mean, how would, how do we teach about the culture in the book to a group of kids? Kids who are culturally diverse? My classroom is really not diverse, so would it be how I used this book in class?

The instructor: You don't necessarily have to have a book about a "different culture" to practice culturally relevant teaching. It doesn't just apply to kids who are from diverse cultures either. Remember, we talked about that. That's not what the teachers in Ladson-Billings's book were doing. What do you think?

Kristyn: I guess what I am understanding, what you want us to do here is use culturally relevant teaching strategies in reading the book to the kids. So then it doesn't have to be a book about the Eskimos or a Japanese boy? That's how I am interpreting this.

The instructor: You're right. Remember, too, that culturally relevant teaching is not a strategy either. Yes, take the idea of culturally relevant teaching and think about what you can do with this. Revoice this idea. Give it your own interpretation in the read aloud. Read aloud is something that you do almost every day, most of you, so I want you to think about culturally relevant teaching as situated in this popular literacy activity.

Clearly, the candidates were confused about the assignment. The confusion emerged from the fact that (1) teaching about different cultures and embedding culturally relevant pedagogy in teaching are two different things and (2) the literacy event that that they were asked to role play (a read aloud) and that Ladson-Billings writes about (the urban high school English classroom where teacher and students are grappling with the idea of standard English and African American Vernacular) are different. It is important to note that the candidates in this class are mostly Caucasian women who teach in middle class neighborhoods so the tension between the examples in The Dreamkeepers and the teachers' own classrooms was high.

After much deliberation and discussion on what exactly the assigned group activity was, the literacy candidates went to work. When the class came back together as a whole group to role play and discuss the small group assignment, one student, Alex, made a comment, or rather to use her words, a "warning" just before her group was about to act out their read-aloud: "I just have to warn you though, before we do our acting out, I mean, we tried our best, but it doesn't look anything like culturally relevant teaching in the book [The Dreamkeepers]." Alex's group enacted a scene and their interactions are illustrated in the below vignette.

Alex's group chose the book, "Chicken Sunday" by Patricia Polacco (1992), a well-known children's author. Alex is an in-service teacher and she had just read the book to her group of kindergarteners a few weeks before. She mentioned that the children's responses in the scenario that her small group was about to enact were actual responses from kindergarteners in her classroom. Alex played the role of the teacher and other candidates in her group acted as the students in Alex's class. ("T" is teacher, "S" are students designated as kindergarten students). The group comes to the front of the classroom to act out their read aloud.

T: Well, today we are going to read this book together, Chicken Sunday. Can anybody guess what this book might be about? (She shows those acting as children the cover of the book).

S: It's about ice cream, chicken flavor ice-cream.

$\mathrm{T}$ : Oh, an ice cream sundae, is that what you're thinking about?

S: Yup.

T: Okay, let's write that down on the board. (Writes "Chicken-flavor ice cream" on the blackboard.) Has anyone 
tasted chicken flavor ice cream?

Students in unison: Nooooo.

T: Okay, what else could it be about? Let's all look at the picture closely.

S: It's about having chicken on Sunday. Like my family, we have chicken on Sunday.

T: Alright. Let's write that down too (Writes "Chicken on Sunday" on the blackboard).

S: Chicken on Sunday.

T: Is it about eating chicken on Sunday or is it about eating chicken flavor ice -cream sundaes?

S: I think it's about family because it has like a picture of a family on the front.

T: Oh, okay. So maybe it's about families eating something and families doing things together?

Well, let's write that down too (Writes, "Families doing things together" on the board). So, it may be about families and what they do. Some families they eat ice cream on Sundays, some families eat chicken on Sundays. My family, we don't do anything on Sunday - we just relax.

What followed were the candidates acting as children commenting on each and every page as the teacher (Alex) read the book and the teacher's (Alex's) efforts to take each comment and weave it into the on-going discussion and the content of the book.

\subsection{Revoicing culturally relevant teaching}

As Alex had "warned" us prior to the performance, this scenario did not resemble anything the master teachers in The Dreamkeepers (Ladson- Billings, 1994) did. Culturally relevant teaching had to be reinterpreted as it now had to be conveyed through interaction within a different situated practice, namely, a read aloud in a mostly middle-class kindergarten classroom. It had to be revoiced (Bakhtin, 1981). What the teachers in The Dreamkeepers (Ladson-Billings, 1994) did, the specific strategies that they used, were of little use to the teachers in Alex's group. The students could not take any strategy/activity from the book and use it in the read aloud. Instead, they had to look for principles underlying the examples presented and underlying Ladson-Billings's explanations of culturally relevant teaching. They then had to use those underlying principles as, to borrow from Dyson, "tools to think with" (2002, p. 18). The idea behind the book's examples were not the objects of study but rather, they became tools to help the in-service teachers think. The principles of culturally relevant pedagogy represented in the book had to be revoiced to become applicable to their setting.

The candidates' performance suggests that "culture" was discursively redefined in the process of integrating the idea of culturally relevant teaching with their read-aloud activity. In revoicing the concept to fit the context of their enacted scenarios, culture now took on broader and more subtle definitions, such as differences in the children's family experiences, differences in their reading abilities, and differences in prior knowledge. This meant being sensitive to the subtle and not so subtle nuances of the children's range of responses and making sure that each response became a part of the class discussion. It also meant, to a certain extent, becoming critically aware of and questioning the hierarchical relationship between the teacher and the students (Ladson-Billings, 1994).

In this example, successfully employing culturally relevant teaching required Alex to temporarily leave her personal understanding of the meaning of "Chicken Sunday" in the background and to resist the urge to teach the "right" meaning of the title. By doing so, her teacher perspective did not overpower the children's personal understandings which were influenced by their various cultural frameworks and experiences with families as well as their experiences with and knowledge of the written system (sundae versus Sunday). A range of cultures, including the teacher's own, were now on the table and as the teacher, it was her job to establish a conceptual map of some sort that established "relevance" for of the children's responses as well as for the collective group.

Ladson-Billings (1994) indicates that one of the most important aspects of culturally relevant pedagogy is equal access to the learning resources - in this case, the classroom discussions. One of the most important things that happened in the role-play was the teacher's validation of each and every student's response regardless of their academic proficiency or their familiarity with the written symbol system and literary themes. According to Gay (2000), creating a validating and accepting learning environment is the cornerstone of culturally responsive teaching. Alex's interpretive framework of the situation - culturally relevant pedagogy - played a critical role in facilitating the flexibility she exercised in her interactions with the students.

Soon after all four groups had their turn acting out their scenarios, one student, Janice, made the below comment.

Well, at first I didn't know why we were even doing this. Even when I was in the middle of the role playing I 
couldn't see the purpose of this activity. But after seeing everyone's, all the groups, now I get it. I know why you wanted us to do this. It makes more sense now. We have to take the idea and we have to use it, transform it. I get it now (Janice, $2^{\text {nd }}$ year first-grade teacher).

\section{Discussion and Conclusion}

As teacher educators, our main goal is to nurture teachers as knowledgeable and reflective practitioners. Drawing from Bakhtin's (1981) notion of "revoicing," we have described a process of putting reflection into action within a teacher education literacy methods class. The major effort is to discuss the process of creating contexts in teacher education classes that help teachers in understanding the not-so-familiar tales and using them, as Dyson (2002) put it, as materials to further our understandings of teaching and learning. We strongly feel that a deep sense of teacher reflection-in-action and reflection-on-action become possible when candidates are able to revoice and therefore reappropriate others' ideas for their own practices.

\subsection{The Need for Revoicing in Re-establishing Teacher Professionalism}

In this paper, we conceptualize reflection as constant reinterpreting and "voicing again" of the theories to meet the realities of our own pedagogical tales (Dyson, 2002). As we illustrated through our example, this process often requires participants to stretch, to reshape, and to reconceptualize conceptual understandings and most importantly, to revisit the different dimensions and dynamics inherent in their own teaching and learning contexts. This is not an easy charge given the political climate of teaching in the United States, under new laws, and even more regulations. The macroclimate of education in this country is not one that is conducive to reflection, or put another way, to thinking about what we do, why we do what we do, and "what what we do does" (Foucault, personal communication, as cited in Dreyfus \& Rabinow, 1983, p. 187). Such a climate does not challenge teachers and teacher candidates to ponder the local sociocultural, political, and economic contexts of their classrooms and the lives of their students. Rather, universalized and prescribed curriculum delivered to teachers with specific timelines and a set of must-do class activities breeds habitual, routine, and programmed ways of teaching and learning focused on meeting the needs of high stakes testing and accountability. Given such realities, this paper is a timely reminder of the importance of reflection in teacher education and the need for concepts that help dismantle the "how-to" of reflective practice.

Reviewing teacher reflection through Bakhtin's (1981) idea of "revoicing" provides an important tool for advancing teachers' professionalism by highlighting the high need of spontaneous yet professional responses in teaching practices. The process of revoicing is the process of orchestrating content knowledge, experience, and one's core educational philosophies that feed what we call our dispositions, and channeling these resources to meet the learning needs of a particular context. As Schön (1983) reminds us, challenges that we encounter in our professional spaces are not always predictable. Indeed, they are not, as we see in classrooms every day and as we illustrated in the example in this paper. It is almost impossible to have prescriptions, however well-planned they may be, to meet or to solve all the challenges that teachers face in classrooms. True teacher professionalism lies in the capacity and the flexibility to bring professional knowledge, experience, and dispositions together in a manner that demonstrates thoughtful orchestration and application of the combined resources for that moment. Teaching is a performance and thus it is at this level of performance where reflection (revoicing) matters. Teaching is a constant artistic performance of revoicing others' voices and the process discovering the meanings and value of one's own pedagogical tales, melodies, and gestures in the process. It is also a process of being able to see how one's own practices are revoiced in other's performances and to notice how the particularities of a certain context - namely the different dimensions and dynamics of the many nested contexts within a teaching and learning setting - alter, limit, but at the same time, provide surprising opportunities for teaching. True revoicing eventually leads to the revoicing of our own theories about teaching and learning and to the revoicing of our dispositions and belief systems that drives everyday decisions that we make on assessment, equal access, culturally relevance, and learning. It is the ultimate resistance against what Seo (2005) calls a "technological rationale" (p. 285) of teaching and teachers teachers as the objects of "saving" content and pedagogical knowledge. When our ideas about teaching are constantly disrupted and revoiced, we add depth and breath to our practice. This is true teacher professionalism.

\section{References}

Bakhtin, M. M. (1981). The dialogic imagination: Four essays. Austin, TX: University of Texas Press.

Bakhtin, M. M. (1986). Speech genres and other late essays. Austin, TX: University of Texas Press.

Dewey, J. (1910/1933). How we think: A restatement of the relation of reflective thinking to the educative process. Chicago, IL: D. C. Heath.

Dreyfus H. L. \& Rabinow, P. (Eds.). (1983). Michel Foucault, Beyond structuralism and hermeneutics $\left(2^{\text {nd }}\right.$ ed.). 
Chicago, IL: The University of Chicago Press.

Dyson, A. H. (2008). Staying in the (curricular)lines: Practice constraints and possibilities in childhood writing. Written Communication, 25, 119-159. http://dx.doi.org/10.1177/0741088307309552

Dyson, A. H. (2002). A Bakhtinian buzz about teacher talk: Discourse matters in "What difference does difference make?" English Education, 35(1), 6-20.

Dyson, A. (1993). Social worlds of children learning to write in an urban primary school. New

York, NY: Teachers College Press.

Gay, G. (2000). Culturally responsive teaching: Theory, research, and practice. New York, NY: Teachers College Press.

Feiman-Nemser, S. (2001) From preparation to practice: Designing a continuum to strengthen and sustain teaching. Teachers College Record, 103(6), 1013-1055. http://dx.doi.org/10.1111/0161-4681.00141

Foucault, M. (1980). Power/knowledge: Selected interviews and other writings, 1972-1977 (C. Gordon, L. Marshall, J. Mepham, \& K. Soper, Trans.). New York, NY: Pantheon Books.

Jay, J. K. \& Johnson, K. L. (2002). Capturing complexity: A typology of reflective practice for teacher education. $\begin{array}{lllll}\text { Teaching } \quad \text { and } & \text { Teacher }\end{array}$ http://www.sciencedirect.com/science/article/pii/S0742051X01000518

Ladson-Billings, G. (1994). The dreamkeepers: Successful teachers of African American children: Successful teachers of African American children. San Francisco, CA: John Wiley \& Sons.

Mewborn, D. S. (1999). Reflective thinking among preservice elementary mathematics teachers. Journal for Research in Mathematics Education, 30(3), 316-341. http://dx.doi.org/10.2307/749838

Miller, J. L. (2005). Sounds of silence breaking: Women, autobiography, curriculum. New York, NY: Peter Lang.

Milner, H. R. (2003). Reflection, racial competence, and critical pedagogy: How do we prepare pre-service teachers to pose tough questions? Race Ethnicity and Education, 6(2), 193-208. http://dx.doi.org/10.1080/13613320308200

Polacco, P. (1992). Chicken Sunday. New York, NY: Philomel Books.

Ringgold, F. (1995). My dream of Martin Luther King. New York, NY: Crown.

Sandoval, D. (1996). Be patient, Abdul. New York, NY: Margaret K. McElderry Books.

Schön, D. (1983). The reflective practitioner: How professionals think in action. New York, NY: Basic Books.

Schön, D. (1987). Educating the reflective practitioner: Toward a new design for teaching and learning in professions. San Francisco, CA: Jossey-Bass.

Seo, K. (2005). Reflection and practice: On the professional development. The Journal of Curriculum Studies. 23(2), 285-310.

Sizer, T. R. (2004). Horace's compromise: The dilemma of American high schools. New York, NY: Houghton Mifflin.

Takabayashi, M. (2001). I Live in Tokyo. Boston, MA: Houghton Mifflin.

Ward, J. R. \& McCotter, S. S. (2004). Reflection as a visible outcome for pre-service teachers. Teaching and Teacher Education, 20(3), 243-257. http://dx.doi.org/10.1016/j.tate.2004.02.004

\section{Notes}

Note 1. All names are pseudonyms.

Note 2. In New York State where this study was conducted, all teachers are required to obtain a second professional teaching certification within 5 years of their first initial teaching certification. The professional certification requires a masters' degree. Many of the students in this class are in-service teachers who have their initial certification and are already teaching (in-service). However, we also refer to them as teacher candidates because they are in the process of applying for their second certification, in this case in literacy education. 